Objectives: To explore and describe pre-treatment CNS pain response associations with post treatment course of RA disease activity components and patient-physician discrepancy in global disease assessment.

Methods: Patients fulfilling the 2010 ACR/EULAR classification criteria with moderate-severe disease activity (DAS-28>3.2) under stable DMARD treatment were recruited. Patients underwent an fMRI scan, stratified by a whole-brain BOLD positive voxel count threshold of 700 units and randomized to treatment with CZP or placebo in a 2:1 ratio. We descriptively assessed components of RA disease activity (Table $1+2$ ). We summarized the mean results and $95 \%$ confidence intervals of these measurements at study timepoints and compared the 3 study groups at week 12 using one-way ANOVA and post-hoc Tukey tests. Results: 156 eligible patients were screened and 139 (99 females, 71\%) patients with moderate-high disease activity were randomized. ANOVA and pairwise comparisons showed that PGA-VAS improvement was larger in the CZP-H group whereas more similar to that in placebo in the CZP-L group. PhysGA-VAS however was similarly reduced in both CZP groups. Patients in the CZP-L group constantly rated their pain numerically higher than physicians whereas in the CZP-H group an initially higher discrepancy numerically reduced over time.

Conclusion: These results suggest that improved patient global disease activity assessment could be the main driver of improved DAS-28 LDA rates with CZP treatment in patients with a high CNS pain response. Our findings indicate a potential role of $\mathrm{MMR}$ imaging of the brain to further understand disease activity perception in RA patients.

Disclosure of Interests: Hannah Schenker: None declared, Jürgen Rech Consultant of: BMS, Celgene, Novartis, Roche, Chugai, Speakers bureau: AbbVie, Biogen, BMS, Celgene, MSD, Novartis, Roche, Chugai, Pfizer, Lilly, Koray Tascilar: None declared, Melanie Hagen: None declared, Verena Schönau: None declared, Marina Sergeeva: None declared, Mageshwar Selvakumar: None declared, Laura Konerth: None declared, Jutta Prade: None declared, Sandra Strobelt: None declared, Larissa Valor: None declared, Axel Hueber Grant/ research support from: Novartis, Lilly, Pfizer, EIT Health, EU-IMI, DFG, Universität Erlangen (EFI), Consultant of: Abbvie, BMS, Celgene, Gilead, GSK, Lilly, Novartis, Speakers bureau: GSK, Lilly, Novartis, David Simon Grant/ research support from: Else Kröner-Memorial Scholarship, Novartis, Consultant of: Novartis, Lilly, Arnd Kleyer Consultant of: Lilly, Gilead, Novartis,Abbvie, Speakers bureau: Novartis, Lilly, Frank Behrens Grant/research support from:

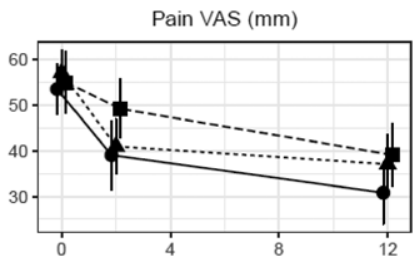

Physician global VAS, mm

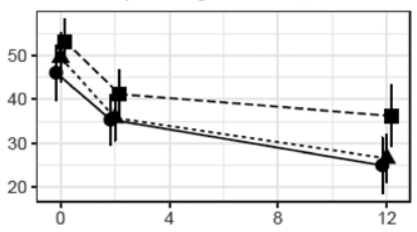

Swollen joint count.*

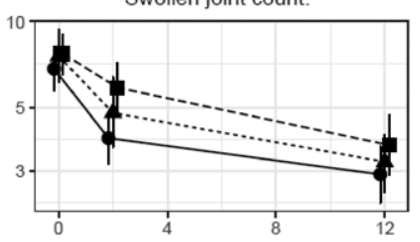

$\mathrm{ESR}, \mathrm{mm} / \mathrm{h}^{*}$

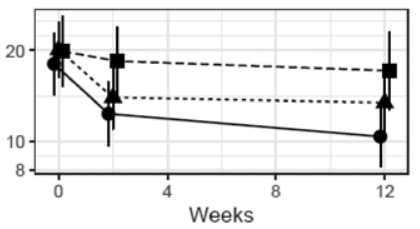

Study group - Certolizumab-High

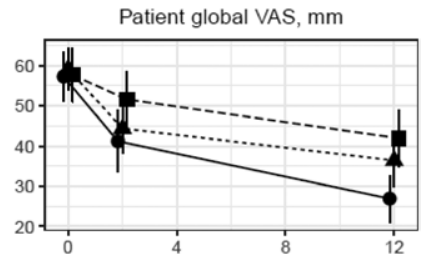

PGA-Phys.GA discrepancy, $\mathrm{mm}^{* *}$

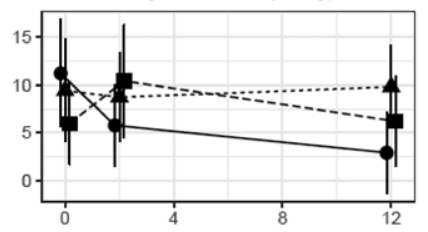

Tender joint count. *

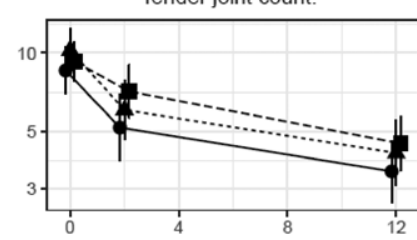

$\mathrm{CRP}, \mathrm{mg} / \mathrm{L}^{*}$

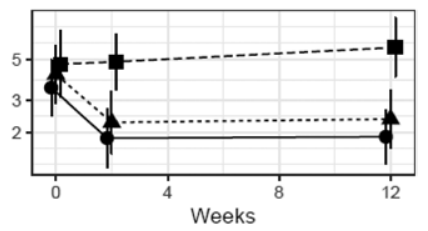

- Certolizumab-Low $\rightarrow$. Placebo

Figure 1. Course of disease activity components through trial timepoints. *indicates log-transformed y axis. ${ }^{*}$ Discrepancy equals Patient global minus physician global assessment.
Table 1: Baseline paticnt characteristics.

\begin{tabular}{|c|c|c|c|c|c|}
\hline & & & \multicolumn{3}{|c|}{ Study group } \\
\hline & & & Certolixumab-Iligh & Certolizumab-Low & Placebo \\
\hline $\mathrm{N}$ & & & 43 & 49 & 47 \\
\hline Age & & $\operatorname{Mean}(\mathrm{SD})$ & $54.3(10.8)$ & $56.5(12.2)$ & $52.1(12.0)$ \\
\hline \multirow[t]{2}{*}{ Sex } & female & $\mathrm{n}(\%)$ & $34(79.1)$ & $35(71.4)$ & $30(63.8)$ \\
\hline & male & $\mathrm{n}(\%)$ & $9(20.9)$ & $14(28.6)$ & $17(36.2)$ \\
\hline \multirow[t]{2}{*}{ Diescase duration } & & Mean(SD) & $6.0(8.3)$ & $6.4(8.6)$ & $6.2(7.6)$ \\
\hline & & Median(IQR) & $2.0(1.0-9.0)$ & $3.0(1.08 .0)$ & $3.0(1.08 .0)$ \\
\hline \multirow{2}{*}{ ACPA } & Negative & $\mathrm{n}(\%)$ & $15(34.9)$ & $9(18.4)$ & $10(21.3)$ \\
\hline & Positive & $n(\%)$ & $28(65.1)$ & $40(81.6)$ & $37(78.7)$ \\
\hline \multirow[t]{2}{*}{$\mathrm{RF}$} & Negative & $\mathrm{n}(\%)$ & $12(27.9)$ & $13(26.5)$ & $14(29.8)$ \\
\hline & Positive & $\mathrm{n}(\%)$ & $31(72.1)$ & $36(73.5)$ & $33(70.2)$ \\
\hline Tender joints (28) & & Mean(SD) & $9.3(6.4)$ & $11.3(6.7)$ & $9.9(6.2)$ \\
\hline Swollen joints (28) & & Mean(SD) & $7.0(4.4)$ & $8.7(6.3)$ & $8.0(4.8)$ \\
\hline Patient global VAS, mm & & Mean(SD) & $57.2(19.9)$ & $59.1(17.8)$ & $57.6(22.5)$ \\
\hline Physician global VAS, mm & & Mean(SD) & $46.0(20.2)$ & $49.5(19.2)$ & $53.1(16.2)$ \\
\hline Pain VAS & & $\operatorname{Mean}(\mathrm{SD})$ & $53.5(18.0)$ & $57.1(17.0)$ & $54.9(22.7)$ \\
\hline ESR & & Mean(SD) & $23.7(19.0)$ & $25.2(17.1)$ & $28.2(23.2)$ \\
\hline CRP & & $\operatorname{Mean}(\mathrm{SD})$ & $6.8(12.7)$ & $7.9(8.7)$ & $11.2(16.5)$ \\
\hline DAS28 & & $\operatorname{Mean}(\mathrm{SD})$ & $4.7(1.0)$ & $5.0(1.1)$ & $4.9(1.0)$ \\
\hline
\end{tabular}

\begin{tabular}{|c|c|c|c|c|}
\hline & Comparison & Difference & $96 \% \mathrm{Cl}$ & P value \\
\hline \multirow{3}{*}{ Pain-VAS } & CZP-L-CZP-II & 6.26 & -4.87 to 17.38 & 0.379 \\
\hline & Placebo-CZP-H & 8.28 & -2.85 to 19.41 & 0.186 \\
\hline & Placebo-CZP-L & 2.02 & -8.85 to 12.89 & 0.899 \\
\hline \multirow[t]{3}{*}{ PGA-VAS } & CZP-L-CZP-H & 9.49 & -1.23 to 20.20 & 0.094 \\
\hline & Placobo-CZP-H & 14.99 & 4.27 to 25.70 & 0.003 \\
\hline & Placebo-CZP-L & 5.50 & -4.97 to 15.97 & 0.429 \\
\hline \multirow[t]{3}{*}{ PhysGA-VAS } & CZP-L-CZP-H & 1.59 & -8.91 to 12.08 & 0.932 \\
\hline & Placebo-CZP-H & 11.22 & 0.67 to 21.77 & 0.034 \\
\hline & Placebo-CZP-L & 9.64 & -0.54 to 19.81 & 0.068 \\
\hline \multirow{3}{*}{ PGA-PhysGA Discrepancy } & CZP-L-CZP-H & 6.90 & -0.50 to 14.30 & 0.073 \\
\hline & Placebo-CZP-H & 3.30 & -4.14 to 10.74 & 0.546 \\
\hline & Placebo-CZP-L & -3.60 & -10.78 to 3.57 & 0.461 \\
\hline \multirow[t]{3}{*}{ SJC-28 } & CZP-LrCZP-H & 0.47 & -1.26 to 2.19 & 0.796 \\
\hline & Placebo-CZP-H & 1.21 & -0.52 to 2.93 & 0.225 \\
\hline & Placebo-CZP-L & 0.74 & -0.95 to 2.43 & 0.554 \\
\hline \multirow[t]{3}{*}{ TJC-28 } & CZP-L-CZP-H & 0.16 & -0.28 to 0.61 & 0.664 \\
\hline & Placebo-CZP-H & 0.25 & -0.20 to 0.69 & 0.389 \\
\hline & Placebo-CZP-L & 0.08 & -0.35 to 0.52 & 0.889 \\
\hline \multirow[t]{3}{*}{ ESR } & CZP-L-CZP-H & 6.53 & -2.80 to 15.85 & 0.225 \\
\hline & Placebo-CZP-H & 11.77 & 2.44 to 21.09 & 0.009 \\
\hline & Placebo-CZP-L & 5.24 & -3.87 to 14.35 & 0.363 \\
\hline \multirow[t]{3}{*}{ CRP } & CZP-L-CZP-H & 0.79 & -7.01 to 8.59 & 0.969 \\
\hline & Placebo-CZP-H & 8.24 & 0.48 to 16.00 & 0.035 \\
\hline & Placebo-CZP-L & 7.45 & -0.17 to 15.07 & 0.057 \\
\hline
\end{tabular}

Abbvie, Pfizer, Roche, Chugai, Janssen, Consultant of: Abbvie, Pfizer, Roche, Chugai, UCB, BMS, Celgene, MSD, Novartis, Biotest, Janssen, Genzyme, Lilly; Boehringer; Sandoz, Speakers bureau: Abbvie, Pfizer, Roche, Chugai, UCB, BMS, Celgene, MSD, Novartis, Biotest, Janssen, Genzyme, Lilly; Boehringer; Sandoz, José Antonio P. da Silva Grant/research support from: Pfizer, Abbvie, Consultant of: Pfizer, AbbVie, Roche, Lilly, Novartis, Christoph Baerwald Consultant of: CGB received speaker or consulting fees from AbbVie, Paid instructor for: CGB received speaker or consulting fees from AbbVie, Speakers bureau: CGB received speaker or consulting fees from AbbVie, Stephanie Finzel: None declared, Reinhard Voll: None declared, Eugen Feist Consultant of: Novartis, Roche, Sobi, Lilly, Pfizer, Abbvie, BMS, MSD, Sanofi, Speakers bureau: Novartis, Roche, Sobi, Lilly, Pfizer, Abbvie, BMS, MSD, Sanofi, Arnd Doerfler: None declared, Nemanja Damjanov Grant/research support from: from AbbVie, Pfizer and Roche, Consultant of: AbbVie, Gedeon Richter, Merck, Novartis, Pfizer, and Roche, Speakers bureau: AbbVie, Gedeon Richter, Merck, Novartis, Pfizer, and Roche, Andreas Hess: None declared, Georg Schett Speakers bureau: AbbVie, BMS, Celgene, Janssen, Eli Lilly, Novartis, Roche and UCB DOI: 10.1136/annrheumdis-2020-eular.5346

\section{OP0219 \\ MORTALITY OF RHEUMATOID ARTHRITIS PATIENTS, TREATED TO TARGET AT LOW DISEASE ACTIVITY: 17-YEARS FOLLOW-UP OF THE BEST COHORT}

J. M. Maassen ${ }^{1}$, Y. Goekoop-Ruiterman ${ }^{2}$, H. Van Groenendael ${ }^{3}$, W. Lems ${ }^{4}$, P. Kerstens ${ }^{5}$, T. Huizinga ${ }^{1}$, C. Allaart ${ }^{1}{ }^{1}$ Leiden University Medical Center (LUMC), Rheumatology, Leiden, Netherlands; ${ }^{2}$ Haga Ziekenhuis, Rheumatology, Den Haag, Netherlands; ${ }^{3}$ Reumazorg Zuid West Nederland, Roosendaal, Netherlands; ${ }^{4}$ Amsterdam UMC loc. VUmc, Rheumatology, Amsterdam, Netherlands; ${ }^{5}$ Dijklander Ziekenhuis, Rheumatology. Hoorn, Netherlands

Background: Rheumatoid arthritis is known to be associated with increased mortality over the years when compared to the general population. In the BeSt study, 508 patients were treated to target (Disease Activity Score $\leq 2.4$ ) for 10 years between April 2000 and August 2012. At the end of the initial study follow-up, the observed mortality in the BeSt cohort was similar to mortality in the general population. In the current study we evaluated the mortality in the BeSt cohort after 17 years follow-up and compared it to the general Dutch population.

Objectives: Evaluate long-term mortality in the BeSt study cohort.

Methods: In the BeSt study 508 patients diagnosed with early RA were randomized to four initial treatment strategies: 1. Sequential monotherapy; 2. Step-up 
combination therapy; 3 . Initial combination therapy with prednisone; or 4. Initial combination therapy with infliximab. During the 10-year follow-up period treatment was steered at low disease activity (DAS $\leq 2.4$ ) and adjusted every three months when necessary. After 10-years patients were treated and followed-up according to regular care. We explored mortality through the Dutch state registry for mortality (Centrum voor Familiegeschiedenis) and treating rheumatologist. Mortality in the BeSt cohort was compared to the general Dutch population (Statistics Netherlands) matched by gender, age and calendar year using the standardized mortality ratio (SMR). Kaplan-Meier curves and the log-rank test were used to compare survival among the initial treatment strategies.

Results: The mean duration of follow-up in non-deceased patients was 17 years (range 16-18). In total, 143 patients died (28\%) compared to a total of $105(21 \%)$ expected deaths in the reference population. The overall SMR after 17 years was 1.37 (95\% Cl: $1.16-1.61)$. Within the study population, no statistically significant difference in survival-curves was observed between the four initial treatment strategies (log-rank $\mathrm{p}=0.76$ ) (table 1, and figure 1).

Table 1. BeSt study cohort mortality - stratified for initial treatment strategy

\begin{tabular}{|c|c|c|c|c|}
\hline & $\begin{array}{c}\text { Sequential } \\
\text { monotherapy } \\
n=126\end{array}$ & $\begin{array}{c}\text { Step-up } \\
\text { combination } \\
\text { therapy } n=121\end{array}$ & $\begin{array}{l}\text { Initial combination } \\
\text { therapy with } \\
\text { prednisone } n=133\end{array}$ & $\begin{array}{c}\text { Initial combination } \\
\text { therapy with } \\
\text { infliximab } n=128\end{array}$ \\
\hline$N(\%) \dagger$ & $38(30)$ & $31(26)$ & $41(31)$ & $33(26)$ \\
\hline SMR $(95 \% \mathrm{Cl})$ & $1.41(1.03-1.94)$ & $1.20(0.84-1.70)$ & $1.53(1.13-2.09)$ & $1.31(0.93-1.85)$ \\
\hline
\end{tabular}

SMR: standardized mortality ratio (number observed deaths/number expected deaths); $\mathrm{Cl}$ : confidence interval.Conclusion:

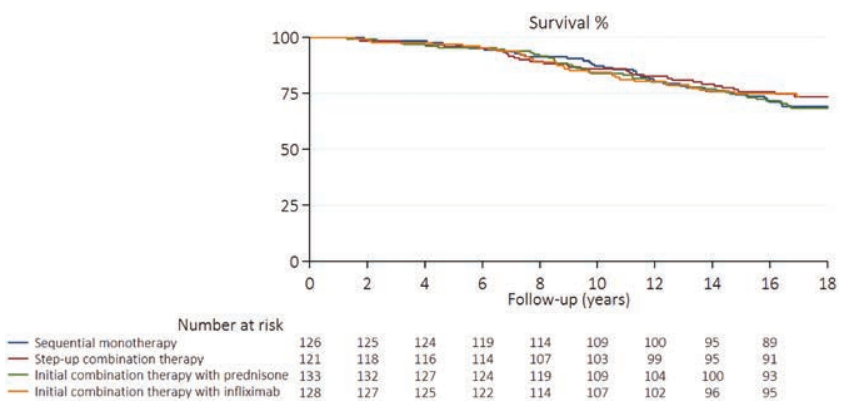

Figure 1. Survival curves - stratified for initial treatment strategy

After a mean of 17 years follow-up the mortality was increased in the BeSt study cohort when compared to the general Dutch population. We observed no difference in survival curves among the four treatment strategies.

Disclosure of Interests: Johanna M. Maassen: None declared, Yvonne Goekoop-Ruiterman: None declared, Hans van Groenendael: None declared, WIllem Lems Grant/research support from: Pfizer, Consultant of: Lilly, Pfizer, Pit Kerstens: None declared, Thomas Huizinga Grant/research support from: Ablynx, Bristol-Myers Squibb, Roche, Sanofi, Consultant of: Ablynx, Bristol-Myers Squibb, Roche, Sanofi, Cornelia Allaart: None declared

DOI: 10.1136/annrheumdis-2020-eular.869

\section{OP0220 ASSESSING THE EFFECT OF INCREASED BODY MASS INDEX ON RESPONSE TO TNF INHIBITORS IN ESTABLISHED RHEUMATOID ARTHRITIS: RESULTS FROM THE METEOR DATABASE}

M. Dey ${ }^{1,2}$, S. S. Zhao ${ }^{1,2}$, R. J. Moots ${ }^{1,2}$, R. B. M. Landewé ${ }^{3,4}$, N. Goodson ${ }^{1,2}$. ${ }^{1}$ Institute of Ageing and Chronic Disease, University of Liverpool, Musculoskeletal Biology I, Liverpool, United Kingdom; ${ }^{2}$ Aintree University Hospital, Liverpool University Hospitals NHS Foundation Trust, Academic Rheumatology, Liverpool, United Kingdom; ${ }^{3}$ Amsterdam Rheumatology \& Immunology Center, Amsterdam, Netherlands; ${ }^{4}$ Atrium MC, Rheumatology, Heerlen, Netherlands

Background: Rheumatoid arthritis (RA) is associated with increased body mass index (BMI)- $60 \%$ of patients are either overweight or obese. Obesity in RA has been shown to predict reduced response to biologic therapy including tumour-necrosis-factor inhibitors (TNFi) [1]. However, it is not clear whether increased BMI influences response to all TNFi drugs in RA.

Objectives: 1.To explore whether BMI is associated with response to TNFi in patients with established rheumatoid arthritis (estRA), including those newly-starting on these drugs.
Methods: Participants with estRA (>1year since diagnosis) taking biologic medications, registered on METEOR (international database of RA patients) 2008-2013, were included. EULAR response, DAS28 remission (including components), and treatment regimens were recorded at baseline, 6 , and 12 months WHO definitions of overweight $(\mathrm{BMI} \geq 25)$ and obese $(\mathrm{BMI} \geq 30)$ were explored as predictors of TNFi response (good EULAR response and DAS28 remission) using normal BMI as comparator. Logistic and linear regression models (controlling for age, gender, smoking, and baseline outcomes) and sensitivity analyses were performed. Subgroup analyses were performed for grouped TNFi and individual TNFi (infliximab, IFX; adalimumab, ADA; etanercept, ETN).

Results: 247 patients with estRA were taking a biologic at 6 months, and 231 patients were taking a biologic at 12 months. Obese patients taking any biologic were significantly less likely to achieve DAS28 remission (OR $0.33[95 \% \mathrm{Cl} 0.12$ $0.80]$ ) or good EULAR response (OR 0.37 [95\% Cl 0.16-0.81]) after 6 months, compared to those of normal BMl; this was also demonstrated in those co-prescribed methotrexate (DAS28 remission: OR 0.23 [95\% $\mathrm{Cl} 0.07-0.62]$; good EULAR response: OR $0.39[95 \% \mathrm{Cl} 0.15-0.92])$. These associations did not remain statistically significant at the 12 months assessment.

Regarding specific anti-TNF therapies, RA patients treated with monoclonal antibody (-mab) TNFis (IFX/ADA/ GOL) were significantly less likely to achieve good EULAR response at 6 months if they were obese RA $(n=38)$, compared to those of normal weight $(n=44)$ (OR 0.17 [95\%Cl 0.03-0.59]). A similar non-significant difference was demonstrated for DAS28 remission, and 12-month remission. Specifically, obese individuals were significantly less likely to achieve good EULAR response at 6 months with IFX (OR 0.09 [95\% Cl 0.00-0.61]; $n=20$ ), and significantly less likely to achieve DAS28 remission at 6 months when newly-starting ADA (OR 0.14 [95\% $\mathrm{Cl} 0.01-0.96] ; n=17$ ), compared to those of normal weight. There were no significant differences in remission outcomes between individuals of different BMI taking ETN. A small number of individuals stopped taking their respective biologic after 6 months; reason for cessation was not recorded.

Similar outcomes were seen in patients already established on anti-TNF therapy, with overweight and obese individuals less likely overall to be in DAS28 remission at all time points.

Conclusion: In established RA, obesity is associated with reduced treatment response to -mab TNFi. No association between increased BMI and response to ETA was observed. Using BMI to direct biologic drug choice could prove to be a simple and cost-effective personalised-medicine approach to prescribing.

References:

[1] Schäfer M, MeißnerY, Kekow J, Berger S, Remstedt S, Manger B, et al. Obesity reduces the real-world effectiveness of cytokine-targeted but not cell-targeted disease-modifying agents in rheumatoid arthritis. Rheumatology. 2019 Nov 20.

Disclosure of Interests: Mrinalini Dey: None declared, Sizheng Steven Zhao: None declared, Robert J Moots: None declared, Robert B.M. Landewé Consultant of: AbbVie; AstraZeneca; Bristol-Myers Squibb; Eli Lilly \& Co.; Galapagos NV; Novartis; Pfizer; UCB Pharma, Nicola Goodson: None declared DOI: 10.1136/annrheumdis-2020-eular.1084

\section{OP0221 \\ HAVE 5-YEAR SURVIVAL RATE AND MORTALITY CHANGED IN PATIENTS WITH EARLY RHEUMATOID ARTHRITIS IN THE PAST TWENTY YEARS?-RESULTS FROM THE IORRA COHORT}

N. Sugitani ${ }^{1}$, E. Tanaka ${ }^{1}$, E. Inoue ${ }^{1,2}$, M. Abe ${ }^{1}$, E. Sugano $^{1}$, K. Saka ${ }^{1}$, M. Ochiai ${ }^{1}$, Y. Shimizu ${ }^{1}$, R. Yamaguchi ${ }^{1}$, N. Sugimoto ${ }^{1}$, K. Ikari ${ }^{3}$, A. Nakajima ${ }^{1,4}$, A. Taniguchi ${ }^{1}$, H. Yamanaka ${ }^{1,5}$, M. Harigai ${ }^{1} .{ }^{1}$ Department of Rheumatology, Tokyo Women's Medical University School of Medicine, Tokyo, Japan; ${ }^{2}$ Division of Medical Informatics, St. Marianna University School of Medicine, Kanagawa, Japan; ${ }^{3}$ Department of Orthopedic Surgery, Tokyo Women's Medical University, Tokyo, Japan; ${ }^{4}$ Center for Rheumatic Diseases, Mie University Hospital, Mie, Japan; ${ }^{5}$ Rheumatology, Sanno Medical Center, Tokyo, Japan

Background: The mortality of patients with rheumatoid arthritis (RA) had been reported as being worse than that of the general population [1, 2], but is expected to have improved over time because the progress in treatment of RA during the past twenty years has been actively adopted to RA management [3 4]. However, the change in the mortality still remains controversial in patients with early RA $[5,6]$

Objectives: To investigate whether the vital prognosis of patients with early RA has changed in the past twenty years.

Methods: The IORRA cohort is a large observational cohort established in 2000 at the Institute of Rheumatology, Tokyo Women's Medical University. Essentially, all Japanese patients diagnosed with RA at our institute were registered and clinical parameters were assessed biannually. As there is no National Death Registry in Japan, we obtained death report from residual families who responded to our mail query to patients who failed to conduct the subsequent IORRA survey, from physicians of affiliated hospitals and from police in case they found dead 